\title{
Clinical Applications of FDG PET and PET/CT in Head and Neck Cancer
}

\author{
Akram Al-Ibraheem, Andreas Buck, Bernd Joachim Krause, Klemens Scheidhauer, \\ and Markus Schwaiger
}

Department of Nuclear Medicine, Technische Universität München, Ismaninger Strasse 22, 81675 Munich, Germany

Correspondence should be addressed to Akram Al-Ibraheem, akramalibrahim@gmail.com

Received 28 February 2009; Accepted 17 June 2009

Recommended by Paul Harari

\begin{abstract}
18F-FDG PET plays an increasing role in diagnosis and management planning of head and neck cancer. Hybrid PET/CT has promoted the field of molecular imaging in head and neck cancer. This modality is particular relevant in the head and neck region, given the complex anatomy and variable physiologic FDG uptake patterns. The vast majority of 18F-FDG PET and PET/CT applications in head and neck cancer related to head and neck squamous cell carcinoma. Clinical applications of 18F-FDG PET and PET/CT in head and neck cancer include diagnosis of distant metastases, identification of synchronous 2nd primaries, detection of carcinoma of unknown primary and detection of residual or recurrent disease. Emerging applications are precise delineation of the tumor volume for radiation treatment planning, monitoring treatment, and providing prognostic information. The clinical role of 18F-FDG PET/CT in N0 disease is limited which is in line with findings of other imaging modalities. MRI is usually used for T staging with an intense discussion concerning the preferable imaging modality for regional lymph node staging as PET/CT, MRI, and multi-slice spiral CT are all improving rapidly. Is this review, we summarize recent literature on 18F-FDG PET and PET/CT imaging of head and neck cancer.
\end{abstract}

Copyright (C) 2009 Akram Al-Ibraheem et al. This is an open access article distributed under the Creative Commons Attribution License, which permits unrestricted use, distribution, and reproduction in any medium, provided the original work is properly cited.

\section{Introduction}

In 2008, head and neck cancers accounted for approximately $4 \%$ to $5 \%$ of all the malignant disease in the United States [1]. Head and neck squamous cell carcinoma (HNSCC) comprises the vast majority of head and neck cancer (HNC). Oncologic imaging plays an important role in head and neck cancers as imaging findings can aid significantly detection, staging, restaging, and therapy response assessment of these tumors. Accurate staging at the time of diagnosis is critical for selection of the appropriate treatment strategy. Unfortunately, at the time of initial diagnosis more than $50 \%$ of patients already present with regional nodal metastases or even distant metastases.

Diagnosis of a head and neck cancer is usually achieved by a combination of patient history, physical examination, and either nasopharyngoscopy and/or laryngoscopy with directed biopsies. Panendoscopy may be necessary to reveal the extent of a tumor. Morphologic imaging with computed tomography (CT) and/or magnetic resonance imaging (MRI) with intravenous contrast are often performed either prior to panendoscopy to noninvasively assess the aerodigestive tract or afterwards to provide information about primary tumor size, infiltration, involvement of surrounding structures, and regional nodal involvement. There is growing evidence, however, that these modalities have limitations in their diagnostic accuracy. CT and MR imaging rely on criteria of contrast-enhancement patterns and nodal size for detection of lymph node metastases which are not specific and may escape detection of metastases within normal size lymph nodes. There is also growing evidence that $18 \mathrm{~F}-\mathrm{FDG}$ PET imaging is a very sensitive and valuable imaging tool in evaluation head and neck cancer. The main drawback of 18F-FDG PET alone is the limitation with respect to lesion localization. However, the advent of PET/CT now overcomes this limitation and permits the evaluation of both metabolic and anatomic characteristics of disease, which has proven to be a major advance for staging, detection carcinoma of 
TABLE 1: Studies comparing accuracy of FDG PET and PET/CT with CT and MRI for detection of lymph nodes metastases.

\begin{tabular}{|c|c|c|c|c|}
\hline Author year & Number of patients & Tumor Subtypes & Results & Notes \\
\hline Beak et al. [2], 2009 & 15 & Periorbital & $\begin{array}{l}\text { PET/CT accuracy }(98 \%)> \\
\text { CT } 84 \%\end{array}$ & $\begin{array}{l}\text { - CT: } 16 \text { slice. } \\
\text { - PET modified Tx in 39\% }\end{array}$ \\
\hline Roh et al. [3], 2007 & 167 & HNSCC & $\begin{array}{l}\text { PET or PET/CT accuracy } \\
(92 \%-93 \%)>\text { CT/MR } \\
85 \%-86 \%\end{array}$ & $\begin{array}{l}\text { - PET/CT significantly } \\
\text { better for detection of } \\
\text { primary tumor }\end{array}$ \\
\hline Gordin et al. [4], 2007 & 35 & Nasopharyngeal & $\begin{array}{l}\text { PET/CT accuracy } 91 \%> \\
\text { PET } 80 \%>\text { CT } 60 \%\end{array}$ & $\begin{array}{l}\text { - Retrospective } \\
\text { - PET/CT modified TX in } \\
57 \%\end{array}$ \\
\hline Kim et al. [5], 2007 & 32 & Oropharyngeal & $\begin{array}{l}\text { PET sensitivity } 21 \% \text { higher } \\
\text { than CT/MR }(P<.05)\end{array}$ & $\begin{array}{l}\text { - PET/CT significantly } \\
\text { better for detection of } \\
\text { primary tumor }\end{array}$ \\
\hline Dammann et al. [6], 2005 & 79 & Oral cavity and oropharynx & $\begin{array}{l}\text { PET accuracy } 96 \%>\text { MRI } \\
94 \%>\text { CT } 92 \%\end{array}$ & - Nonhyprid PET/CT used \\
\hline Ng et al. [7], 2005 & 124 & Oral cavity SCC & $\begin{array}{l}\text { PET accuracy } 98.4 \%> \\
\text { CT/MR } 87.1 \%\end{array}$ & - Prospective \\
\hline
\end{tabular}

unknown primary, treatment monitoring, and evaluation of residual or recurrent disease.

\section{Staging}

Accurate staging at the time of diagnosis is the most important factor for treatment planning and determination of prognosis [8]. One attractive feature of 18F-FDG PET as a modality for initial TNM staging is that it covers most of the body within a single study. PET therefore provides information on the primary tumor, nodal metastases, distant metastases, and potential 2 nd primary carcinomas. A literature survey on the use of 18F-FDG PET in head and neck cancer (HNC) compared to CT indicates that PET has a higher sensitivity (87\% versus $62 \%$ ) and specificity $(89 \%$ versus 73\%) for staging cancer [9]. Addition of PET/CT to initial staging of patients with HNC has also been shown to have a measurable impact on the treatment selection $[10,11]$.

2.1. Primary Tumor. Numerous reports on initial staging have shown that $18 \mathrm{~F}-\mathrm{FDG}$ PET is at least as sensitive as MRI or CT in detecting the primary tumor [3, 7, 10-17]. This is related to the fact that smaller or submucosal malignancies may be difficult to distinguish from adjacent tissues on anatomical imaging. A better sensitivity of 18F-FDG PET for detecting primary tumor comparing to CT/MRI imaging has been shown in oral cavity cancer $[18,19]$. However, the current practice is not in favor of utilizing 18F-FDG PET for local staging of all newly diagnosed head and neck squamous cell carcinoma (HNSCC). This is due to the higher anatomic resolution of MRI and contrast enhanced multislice CT compared to 18F-FDG PET. Nevertheless, in a recent study by Baek et al. including 40 patients with oral cavity cancer and dental artifacts on CT or MRI, it was demonstrated that $18 \mathrm{~F}-\mathrm{FDG} \mathrm{PET} / \mathrm{CT}$ can provide more useful clinical information and higher sensitivity, particularly in deep tumors, compared to CT and MR. The diagnostic performance for the detection of the primary tumors in the oral cavity was $96.3 \%$ for PET/CT, $77.8 \%$ for CT, and $85.2 \%$ for MRI [20].

2.2. Nodal Metastases. Nodal staging has a significant impact on outcome in terms of disease free survival and overall survival after therapy [21]. Metastatic lymph node disease is found in approximately $50 \%$ of the patients at the time of primary diagnosis $[6,22]$. Several reports have verified that 18 F-FDG PET has a higher sensitivity and specificity than CT or MR imaging for detection of lymph node metastases in head and neck cancer $[23,24]$. In a review by Schöder and Yeung, an average sensitivity of $87 \%-90 \%$ and a specificity of $80 \%-93 \%$ were reported for $18 \mathrm{~F}-\mathrm{FDG}$ PET/CT; a sensitivity of $61 \%-97 \%$ and specificity of $21 \%-100 \%$ were reported for morphologic imaging modalities including MRI and CT [25]. Several recent studies comparing 18F-FDG PET, 18F-FDG PET/CT, and CT/MR are summarized in Table 1. Results showed that integrated 18F-FDG PET/CT may play an important role in identifying lymph node metastases in head and neck squamous cell carcinoma (HNSCC). However, MRI is usually used for local staging as it provides almost comparable accuracy to $18 \mathrm{~F}-\mathrm{FDG}$ PET in locoregional metastases in addition to best primary tumor delineation [26].

Occult lymph nodes (clinical N0 disease) still represent a dilemma for both imaging modalities and surgeons. Although earlier reports have favored PET over other anatomic imaging modalities as PET has been shown to have a sensitivity of $78 \%$ and an accuracy of $92 \%$ (compared with a sensitivity of $57 \%$ and an accuracy of $76 \%$ for CT) for the detection of nodal metastases in clinical N0 disease [27]. Two recent reports by Nahmias et al. and Schoder et al. comprising 47 and 37 patients, respectively, demonstrated that $18 \mathrm{~F}-\mathrm{FDG}$ PET/CT is not accurate enough for detection 

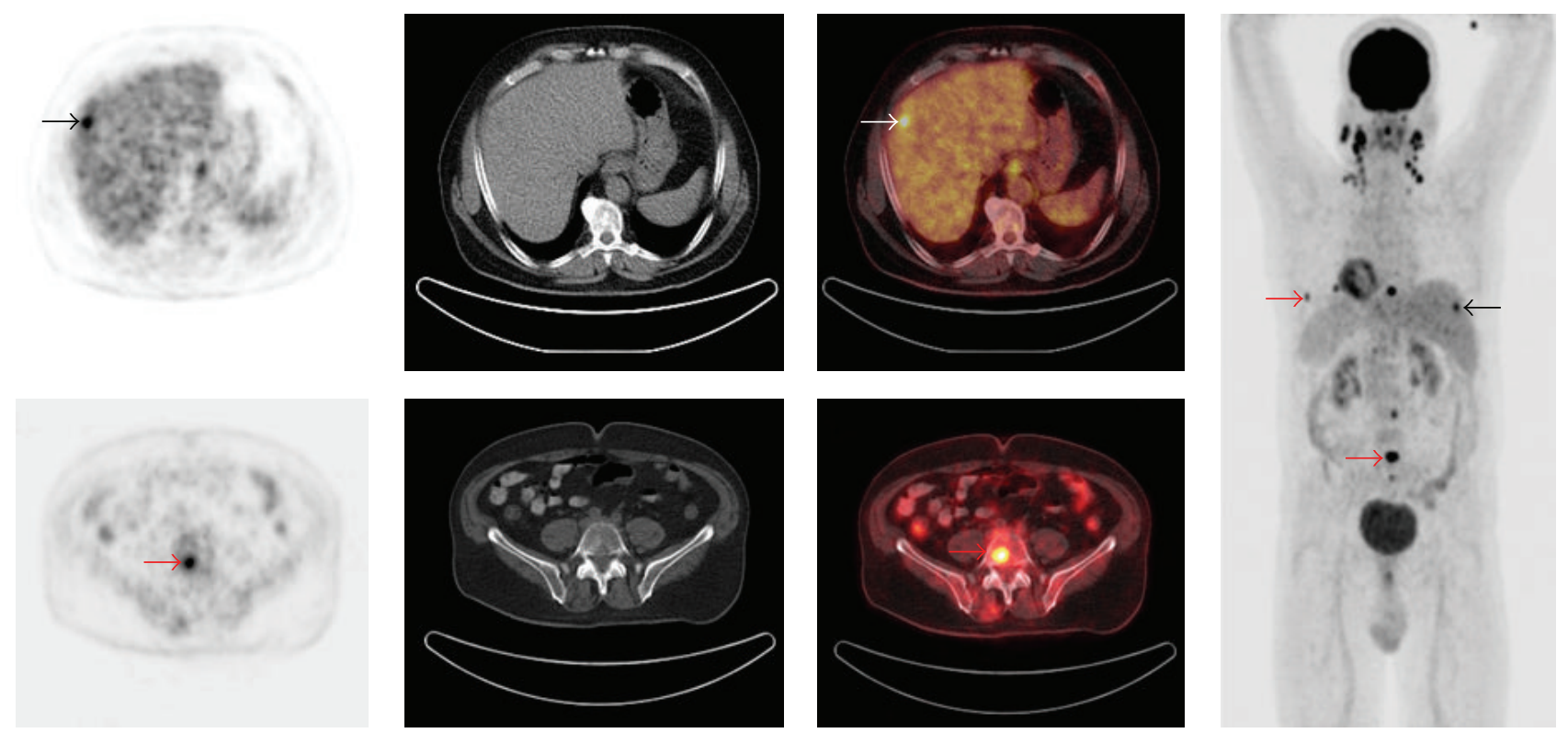

FIgURE 1: A 61-year-old man with nasopharyngeal SCC and bilateral cervical lymph node metastases underwent PET/CT for staging. Axial PET, CT, PET/CT, and maximum intensity projection (MIP) images are shown. PET/CT revealed focal FDG uptake in the right liver lobe indicating liver metastasis (black, white arrows). PET/CT also revealed multiple focal FDG uptakes in the lumbar spine, sternum, and ribs indicating multiple bone metastases (red arrows). PET/CT was valuable for detection distant metastases.

of occult nodal disease in previously untreated patient and would not help the surgeon in the management strategy of the patient, particularly if the study is negative. They reported sensitivity and a specificity ranging from $67 \%$ to $79 \%$ and $82 \%$ to $95 \%$, respectively. False negative findings were likely related to either the presence of microscopic metastases not detected by PET/CT, or by the proximity of nodal metastases to the primary tumor which might have obscured their detection $[28,29]$. Schroeder et al. verified these results and suggested that elective neck dissection in patients with clinical N0 head and neck cancer squamous cell carcinoma (HNSCC) should not be based upon crosssectional imaging (CT, MR, PET/CT) at the resolutions currently available [30]. However, Kovacs et al. examined the potential role of 18F-FDG PET and sentinel node biopsy in 62 patients for the purpose of neck dissection. Their results suggest that patients showing positive lymph node on PET scan undergo a neck dissection due to the high specificity, whereas a sentinel node biopsy should be performed in patients with a negative PET scan. This strategy avoided 12 patients futile neck dissections with false-positive CT findings and a negative sentinel node biopsy [31].

2.3. Distant Staging. The role of 18 F-FDG PET for staging of distant metastases in HNC is acknowledged as one of the most powerful indication in HNC (Figure 1). There is a general agreement that $18 \mathrm{~F}-\mathrm{FDG}$ PET is indicated for initial staging of HNC when there is suspicious of distant metastases and synchronous 2nd tumor. The incidence distant metastases increases with locally advanced disease (T3-T4), N2, or N3 disease, extracapsular extension of lymph node involvement, and perineural invasion $[32,33]$.
A synchronous 2nd tumor, particularly in aerodigestive tract, is often associated with a history of heavy nicotine or alcohol consumption and patients with hypopharyngeal tumors. Recent studies on the use of 18F-FDG PET for the detection of distant metastases and synchronous 2 nd tumor in HNC are summarized in Table 2. These studies showed that PET detected distant metastases or 2 nd primaries in up to $15.6 \%$ of the patients. The true positive findings were $82 \%$. Moreover, PET showed a better accuracy once it was compared to conventional imaging as demonstrated by $\mathrm{Ng}$ et al., Chua et al., and Liu et al. [34-36].

\section{Carcinoma of Unknown Primary}

Cervical lymph node metastases from an unknown primary tumor account for approximately 1-2\% of newly diagnosed head and neck cancers [40]. In 5\% to $80 \%$, depending on the patient selection, the primary tumor could not be identified by physical examination, panendoscopy, and conventional imaging, including CT and/or MRI [41, 42]. Treatment of these patients often includes extensive fields of irradiation to include the entire pharyngeal mucosa, larynx, and bilateral neck. The wide-field irradiation reduces the risk of tumor recurrence. However, it also causes significant morbidity, particularly in terms of xerostomia [43]. Therefore, the accurate identification of occult primary sites is important because the therapy can then be focused to the known site of origin, decreasing treatment-related morbidity, and improving therapeutic efficacy [44].

The utility of 18F-FDG PET to identify carcinomas of unknown primary has been examined. A comprehensive review by Rusthoven summarized the impact of $18 \mathrm{~F}-\mathrm{FDG}$ 
TABLE 2: Studies evaluating the performance of FDG PET for the detection of distant metastases and synchronous 2nd tumor in HNC.

\begin{tabular}{|c|c|c|c|c|c|}
\hline Author year & Number of patients & Positive PET & $\begin{array}{l}\text { True positive (distant } \\
\text { mets }+2 \text { nd primary) }\end{array}$ & False positive & Notes \\
\hline Ng et al. [34], 2009 & 111 & 16 & $13 / 16$ & $3 / 16$ & CT/MR detect 4/16 \\
\hline $\begin{array}{l}\text { Chua et al. [35], } \\
2009\end{array}$ & 68 & 6 & $5 / 6$ & $1 / 6$ & $\mathrm{CT}+\mathrm{BS}$ detect $4 / 6$ \\
\hline Liu et al. [36], 2007 & 300 & 61 & $50 / 61$ & $11 / 61$ & \\
\hline $\begin{array}{l}\text { Yen et al. [37], } \\
2005\end{array}$ & 118 & 32 & $24 / 32$ & $8 / 32$ & \\
\hline $\begin{array}{l}\text { Goerres et al. [12], } \\
2003\end{array}$ & 34 & 8 & $7 / 8$ & $1 / 8$ & PET modified Treatment in 15\% \\
\hline $\begin{array}{l}\text { Sigg et al. [38], } \\
2003\end{array}$ & 58 & 8 & $7 / 8$ & $1 / 8$ & PET modified Treatment in 5\% \\
\hline $\begin{array}{l}\text { Schwartz et al. } \\
{[39], 2003}\end{array}$ & 33 & 7 & $7 / 7$ & $0 / 7$ & \\
\hline Total & 722 & 138 & $113 / 138$ & $25 / 138$ & \\
\hline
\end{tabular}

PET for the situation of carcinoma of unknown primary. A total of 16 studies comprising 302 patients, published between 1994 and 2003, were included. In all of these studies, patients underwent physical examination and CT or MRI, with the majority undergoing panendoscopy as well. The gold standard for primary tumor verification was tissue biopsy. Of the 302 patients, 18F-FDG PET detected 24.5\% of tumors that were not apparent after conventional workup. 18F-FDG PET imaging also led to the detection of previously unknown metastases in $27.1 \%$ of the patients (regional, $15.9 \%$; distant, $11.2 \%$ ). The overall of sensitivity of PET for the primary tumor detection was $88 \%$, with a specificity of $75 \%$, and an accuracy of $79 \%$. When detection efficacy was evaluated with respect to localization, a lower sensitivity for cancers in base of tongue, and a lower specificity for cancers in the tonsil were noted [45]. In this review, we performed a meta-analysis including studies published between 2000 and 2009 that specifically addressed the performance of $18 \mathrm{~F}$ FDG PET or PET/CT in detecting carcinoma of unknown primary in patients presented with cervical lymph node metastases and negative or inconclusive standard workup. For this group, 18F-FDG PET and PET/CT detected the primary tumor in 51 of 180 patients (28\%) (Table 3 ).

Two recent reports in the era of advanced morphologic imaging technology also verified the vital utility of $18 \mathrm{~F}-\mathrm{FDG}$ PET and PET/CT in cancer of unknown origin. Johansen et al. showed in a prospective study comprising 67 patients with cancer of unknown primary that a therapeutic change of treatment was made in $25 \%$ as a consequence of $18 \mathrm{~F}-\mathrm{FDG}$ PET findings [54]. Roh et al. compared the performance of combined 18F-FDG PET/CT and CT alone in 44 patients with cervical metastases from unknown primary tumors. They reported that $18 \mathrm{~F}-\mathrm{FDG}$ PET/CT was significantly more sensitive than CT $(94.0 \%$ versus $71.6 \%, P<.001)$, but the two methods had similar specificities $(94.8 \%$ versus 96.5\%, resp.). 18F-FDG PET/CT correctly detected distant metastases in 6 out of 6 patients [55]. Based on these results, 18F-FDG PET and PET/CT can be recommended as early diagnostic modality in the workup for carcinoma of unknown primary and neck metastases (Figure 2).

\section{Treatment Response Assessment}

In recent years, the use of combined chemoradiotherapy (CRT) has been shown to have a significant impact on the treatment of head and neck cancer [56]. 18F-FDG PET is a valuable modality for monitoring response to treatment as it can assess metabolic activity rendering malignant process. Martin et al. demonstrated in a recent study including 78 patients that PET was significantly superior to clinical examination or conventional imaging with respect to the assessment of patients after chemoradiotherapy. Accuracy of PET in therapy response assessment was significantly better than clinical assessment and conventional imaging (CT/MR) $(P<.002$ and $P<.001$, resp.). The authors also suggested that patients with a complete response on posttreatment PET have a significant survival advantage [57].

Monitoring response to radiation therapy can be complex due to posttreatment changes like inflammation and edema. 18F-FDG PET has been investigated in the assessment of early response to chemotherapy regimen and if modification or discontinuation are needed or not (Figure 3). Several reports have illustrated that patients with favorable response to therapy demonstrate a continued reduction in metabolic activity and hence decreased FDG uptake over multiple PET studies compared to baseline values. Prognostic value of $18 \mathrm{~F}-\mathrm{FDG}$ PET regarding survival and response to therapy appears promising but needs more confirmation.

\section{Residual and Recurrent Disease}

The utility of anatomical imaging in the posttreatment situation is limited because of fibrosis, tissue edema, and anatomical distortion $[58,59]$. The early detection of residual or recurrent head and neck cancer following radiation therapy and/or chemotherapy poses a diagnostic challenge. A survey of the literature showed that 18F-FDG PET is the most sensitive noninvasive modality presently available for differentiating posttreatment changes from residual or recurrent 
TABLE 3: Studies evaluating performance of 18F-FDG PET or PET/CT for the detection of carcinoma of unknown primary in patients with negative workup.

\begin{tabular}{|c|c|c|c|c|c|}
\hline Author year & Number of patients & All positive & True positive & False positive & $\begin{array}{c}\text { Percent detected by } \\
\text { PET }\end{array}$ \\
\hline Padovani et al. [46], 2009 & 13 & 9 & 7 & 2 & $54 \%$ \\
\hline Silva et al. [47], 2007 & 25 & 9 & 3 & 6 & $12 \%$ \\
\hline Fakhry et al. [48], 2006 & 20 & 10 & 7 & 3 & $35 \%$ \\
\hline Wong and Saunders [49], 2003 & 17 & 8 & 5 & 3 & $29 \%$ \\
\hline Fogarty et al. [50], 2003 & 21 & 6 & 1 & 5 & $5 \%$ \\
\hline Johansen et al. [51], 2002 & 42 & 20 & 10 & 10 & $24 \%$ \\
\hline Kresnik et al. [52], 2001 & 15 & 12 & 11 & 1 & $73 \%$ \\
\hline Jungehulsing et al. [53], 2000 & 27 & 7 & 7 & 0 & $26 \%$ \\
\hline Total & 180 & 81 & 51 & 30 & $28 \%$ \\
\hline
\end{tabular}
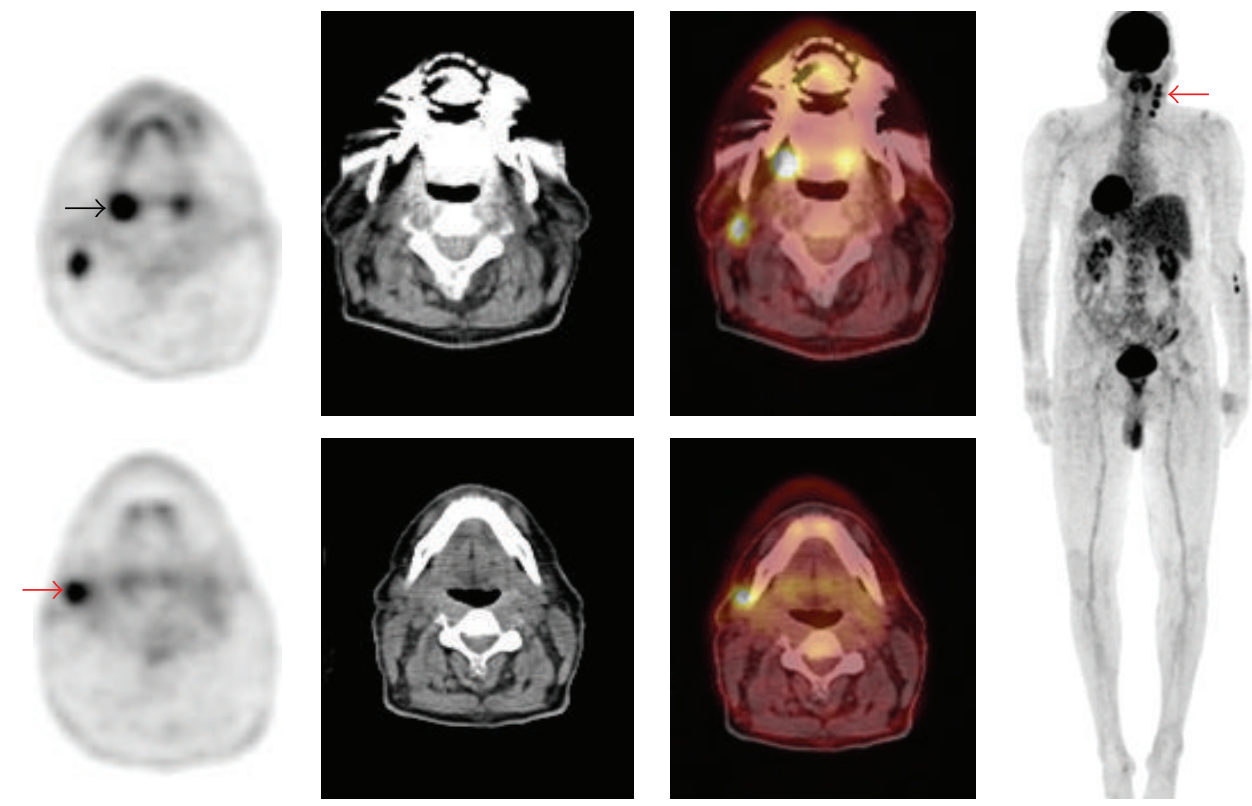

FIGURE 2: A 61-year-old man presented with right side cervical lymphadenopathy proved to be carcinoma of unknown primary. Patient underwent PET/CT to reveal primary tumor. Axial PET, CT, PET/CT, and maximum intensity projection (MIP) images are shown. PET/CT showed asymmetrical FDG uptake in the palatine tonsils with intense FDG uptake in the right tonsil (black arrow) as well as multiple hypermetabolic cervical lymph nodes in the right side (red arrows). This patient subsequently underwent surgical resection and histopathology revealed squamous cell carcinoma in the right tonsil. PET/CT was valuable in revealing the primary tumor in this case.

disease and that its performance is higher compared CT and MR for this purpose.

\section{Residual Disease}

A 3-4 months interval between the end of radiotherapy and evaluation of residual malignant tissue provides the best specificity and sensitivity for PET. This is due to reducing false positive findings associated with nonspecific inflammatory activity, and reducing false negative findings encountered during first 8 weeks postchemoradiotherapy which may increase the risk of seeding the dissection scar if viable tumor cell was left in the tumor bed [60-67]. The NPV of PET following therapy is very high (up to
97\%) and associated with a very good prognosis, whereas positive 18F-FDG PET must be correlated with clinical status and a biopsy is needed to rule out nonspecific uptake [60, 61, 64-67]. Performance of 18F-FDG PET early after chemoradiotherapy has been evaluated to assess residual tumor as many surgeons prefer to perform salvage surgery within 6 to 8 weeks after radiation, before postradiation fibrotic changes develop. Kim et al. found in a prospective study in 97 patients that early imaging one month following completion of radiation therapy can be performed with high sensitivity (88\%) and specificity (95\%) [68]. Delbeke and Martin and Kostakoglu and Goldsmith agreed in two reviews that persistent tumor uptake one month after radiation therapy is strongly suggestive of residual disease and that 

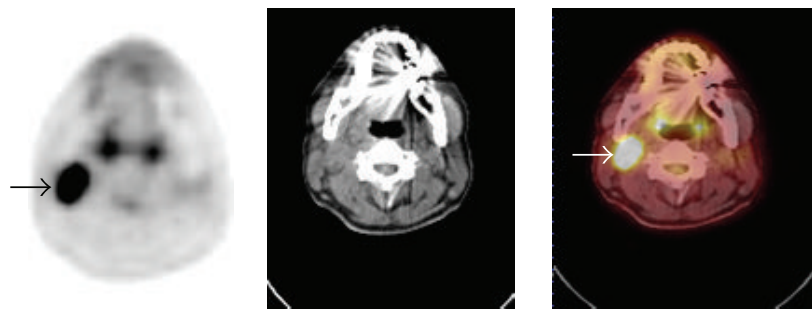

(a)

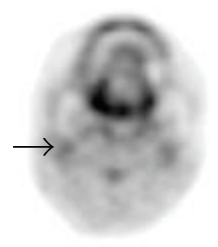

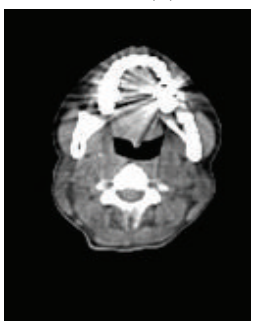

(b)

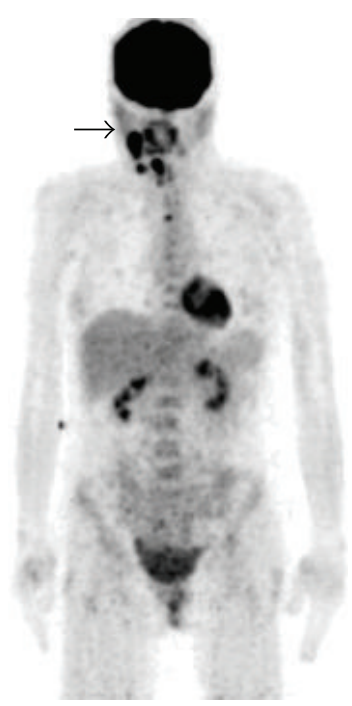

(a)

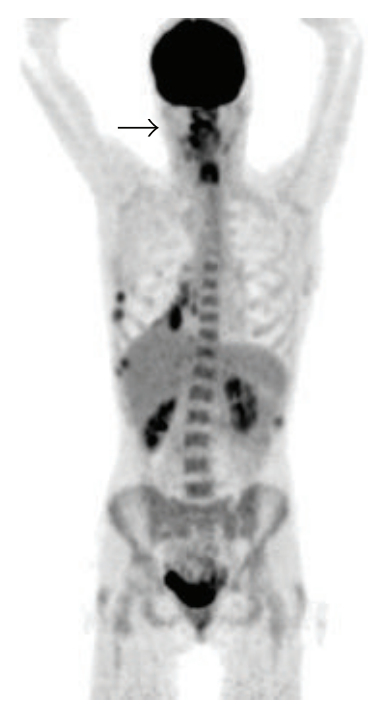

(b)

Figure 3: 40-year-old women with right side larynx squamous cell carcinoma and a right side cervical lymph node metastases underwent PET/CT imaging before and 1 month after completion of chemoradiotherapy. (a) Pretherapy axial PET, CT, PET/CT, and MIP images reveal intense FDG uptake in the right cervical lymph node (arrows). (b) After treatment axial PET, CT, PET/CT, and MIP images reveal decrease FDG uptake in the corresponding locations (arrows). Appearance was consistent with early response to chemoradiotherapy. FDG PET/CT was valuable in monitoring early response to treatment.

a positive PET scan can result in immediate initiation of secondary treatment strategies due to early detection of resistance to chemotherapy $[69,70]$. On the other hand, Rogers et al. found in a prospective study with a small number of patients (12 patients) a low sensitivity of $45 \%$ for a 1-month posttherapy $18 \mathrm{~F}-\mathrm{FDG}$ PET, compared to the 6-8 week posttreatment surgical histopathology [71]. The current role of 18F-FDG PET and PET/CT are indicated to exclude residual disease and to select patients who are candidates for salvage surgery after chemoradiotherapy. Although there is general consensus that waiting 3 months postradiation sustains best sensitivity and specificity, early imaging is justified in some scenarios, but with cautious interpretation considering time interval posttherapy and clinical findings.

The possible role of 18F-FDG PET in avoiding patients futile neck dissection after treatment by excluding residual locoregional disease has also been evaluated. Ong et al. demonstrated in a recent study comprising 65 patients that $18 \mathrm{~F}-\mathrm{FDG}$ PET/CT has a high negative predictive value (NPV) and specificity (97\% and 89\%, resp.) for excluding residual locoregional disease after chemoradiotherapy and that neck dissection may be omitted safely in patients without lymphadenopathy, while in patients with residual lymphadenopathy, a lack of abnormal ${ }^{18} \mathrm{~F}-\mathrm{FDG}$ uptake in these nodes also excludes viable tumor with high certainty but still further assessment is needed [72]. Yao et al. suggested that 18F-FDG PET can avoid patient neck dissection if the postradiotherapy 18F-FDG PET scan is negative since it has had a high predictive value for negative pathology in neck dissection or fine-needle aspiration even with large residual lymphadenopathy [73]. Nevertheless, Tan et al. found in a retrospective study comprising 48 patients that $18 \mathrm{~F}-\mathrm{FDG}$ PET was not a good predictor of residual disease [74]. Standardization of the role of 18F-FDG PET in avoiding neck dissection in a prospective study particularly when lymphadenopathy presents is necessary before negative $18 \mathrm{~F}$ FDG PET/CT may become the only, or at least mostdecisive, criterion in the management of the neck after chemoradiotherapy.

\section{Recurrence}

Klabbers et al. reviewed studies published between 1994 and early 2003 regarding the utility of 18F-FDG PET for detection of residual and recurrent head and neck tumors after radiation and/or chemoradiotherapy. The results showed that 18F-FDG PET has a better sensitivity (86\%) and specificity (73\%) compared with CT and/or MRI (56\% sensitivity and 59\% specificity, resp.) [75]. Ryan et al. reported on 108 patients and found that 18F-FDG PET/CT detected locoregionally persisting or recurrent head and neck SCC with a sensitivity of $82 \%$, a specificity of $92 \%$, a positive predictive value (PPV) of $64 \%$, a negative predictive value (NPV) of $97 \%$, and an overall accuracy of $90 \%$ [76].

18F-FDG PET and PET/CT have a high sensitivity and moderate specificity for detecting recurrent disease at the primary tumor site, regional lymph node metastases, and distant metastases. Wong performed a meta-analysis on studies published between 1999 and 2002 that showed relatively high sensitivity (84-100\%) with moderate specificities (6193\%) regarding 18F-FDG PET in recurrent tumor of HNCSC [84]. Several studies published in the last 4 years on the utility of PET or 18F-FDG PET/CT for the detection of recurrence 
TABLE 4: Studies evaluating the performance of 18F-FDG PET and PET/CT for the detection of recurrent disease in head and neck cancers.

\begin{tabular}{|c|c|c|c|c|c|}
\hline Authors year & Number of patients & Sensitivity & Specificity & Accuracy & Notes \\
\hline Abgral et al. [77], 2009 & 91 & $100 \%$ & $85 \%$ & $90 \%$ & FDG PET/CT \\
\hline Wang et al. [78],2009 & 44 & $100 \%$ & $98 \%$ & $98 \%$ & $\begin{array}{l}\text { Prospecrive } \\
\text { PET performance }>\mathrm{CT}\end{array}$ \\
\hline Cermik et al. [79], 2007 & 50 & $83 \%$ & $93 \%$ & & \\
\hline Álvarez Pérez et al. [80], 2007 & 60 & $98 \%$ & $90 \%$ & & Prospective \\
\hline Salaun et al. [81], 2007 & 30 & $100 \%$ & $95 \%$ & $97 \%$ & \\
\hline Goerres et al. [82], 2004 & 26 & $91 \%$ & $93 \%$ & & Prospective \\
\hline Kubota et al. [83], 2004 & 36 & $90 \%$ & $78 \%$ & $81 \%$ & $\begin{array}{l}\text { Prospective } \\
\text { Accuracy significantly higher } \\
\text { than CT/MR }\end{array}$ \\
\hline
\end{tabular}

are summarized in Table 4 . The performance of PET with respect to the identification of recurrent disease following treatment demonstrated a high sensitivity $(83 \%-100 \%)$ and relatively high specificity $(78 \%-95 \%)$. The higher specificity in these studies compared to an earlier report, published by Wong et al., may be related to more awareness of proper time point (2-3 months) for imaging after treatment.

\section{PET/CT in Radiation Treatment Planning}

New high-precision radiotherapy (RT) techniques, such as intensity-modulated radiation therapy (IMRT), 3dimensional conformal radiotherapy (3D-CRT), and proton beam therapy allow conformal treatment of tumor and to avoid unacceptable damage to normal tissues leading to possible improvement of tumor control and decrease of treatment-related toxicity. These techniques depend on imaging modalities allowing accurate tumor volume delineation and response assessment during treatment. The potential application of 18F-FDG PET/CT for intensity modulated radiation therapy (IMRT) planning is an area of major interest. PET/CT may increase the gross target volume (GTV) because metabolically active tumor can be detected in normal-sized nodes. On the other hand, PET/CT-based target volume could be smaller than CT-based target volume alone in the case of patients in whom the tumor may be partially necrotic. The radiation treatment plan might be modified significantly if distant metastases are detected on the PET scan. The radiation target volumes may be significantly modified when 18F-FDG PET data are incorporated into radiation treatment planning. However, PET has been found to fail frequently to identify viable tumor in areas of bone marrow infiltration and perineural extension that are highly suspect on MRI (21).

Soto et al. suggested recently, based on a retrospective study comprising 61 patients, that 18F-FDG PET/CT should play an important but not exclusive role in defining the gross target volume (GTV) depending on the correlation between pretreatment 18F-FDG PET-defined biologic target volume (PET-BTV) and the anatomical sites of locoregional failure (LRF) after 3-D CRT or IMRT for head and neck cancer [85].
Rothschild et al. reported in a recent case control analysis of 45 patients with pharyngeal carcinoma that PET/CT and treatment with IMRT improved cure rates compared to patients undergoing IMRT without PET/CT. The event-free survival rate of the PET/CT-IMRT group was $90 \%$ and $80 \%$ at 1 and 2 years, respectively, compared to $72 \%$ and $56 \%$ in the control group without PET/CT $(P=.005)$ [86].

Wang et al. investigated 28 patients with head and neck carcinoma treated with IMRT based on an 18FFDG PET/CT defined gross tumor volume (GTV). They reported that tumor staging was significantly changed in $50 \%$ of cases (14/28 patients) as compared with CT-based staging, with 12 patients having higher $\mathrm{T}$ stages and 6 patients having higher $\mathrm{N}$ stages. Furthermore, a 17 months median follow-up period posttherapy did not reveal any locoregional recurrence indicating that PET-guided planning of the radiation field is accurate [87].

On the other hand, Breen et al. reported that GTV assessment in 10 patients with HNSCC was not significantly different between PET/CT and contrast CT scans, using 8 different observers. Furthermore, Breen et al. noted that there was greater consistency for the CT derived GTV's compared to the PET/CT derived volumes [88]. Table 5 summarizes recent studies on the use of 18F-FDG PET in radiotherapy planning. Ahn and Garg suggested in a review that the utility of a functional assay in defining target volume helps to determine areas to receive higher doses of radiation in cancers of the head and neck tumors [94].

One of the most controversial and challenging issues in applying PET/CT in radiation planning is contouring the outline of the tumor. Changing the PET window level can lead to a considerable overestimation or underestimation of the target volume. However, several techniques including threshold-based methods and gradient-based methods have been suggested and used, but still consensus needs to be met. Fifty percent of the tumor/image maximum intensity have been used for contouring by several groups $[9,95]$. Others normalized volumes according to liver uptake [89, 91]. Wang et al. used an arbitrary SUV of 2.5 as a basis for contouring [87]. Berson et al. suggested in a recent report that developing an institutional contouring protocol 
TABLE 5: Studies evaluating the role of FDG PET and PET/CT in radiation planning.

\begin{tabular}{|c|c|c|c|c|}
\hline Author year & Number of patients & Study type & Results & Notes \\
\hline $\begin{array}{l}\text { Soto et al. [85], } \\
2008\end{array}$ & 61 (9 LRF) & Retrospective & 8/9 LRF within BTV-PET. & \\
\hline $\begin{array}{l}\text { Rothschild et al. } \\
{[86], 2007}\end{array}$ & 45 & Case-control analysis & $\begin{array}{l}\mathrm{PET} / \mathrm{CT} \text { with IMRT improved } \\
\text { cure rates }\end{array}$ & $\begin{array}{l}\text { Advanced pharyngeal } \\
\text { carcinoma }\end{array}$ \\
\hline $\begin{array}{l}\text { Wang et al. [87], } \\
2006\end{array}$ & 28 & Prospective & $\begin{array}{l}\text { PET/CT-based GTV significantly } \\
\text { different from CT scans alone in } \\
50 \% \text { of cases }\end{array}$ & $\begin{array}{l}\text { PET/CT upgraded T } \\
\text { and } \mathrm{N} \text { stage in } 18 \mathrm{p} \text {. }\end{array}$ \\
\hline $\begin{array}{l}\text { Breen et al. [88], } \\
2007\end{array}$ & 10 & & $\begin{array}{l}\text { no significant differences in the } \\
\text { GTVs between PET/CT and CT } \\
\text { alone }\end{array}$ & $\begin{array}{l}\text { CT volumes were } \\
\text { larger than PET-CT }\end{array}$ \\
\hline $\begin{array}{l}\text { El-Bassiouni et al. } \\
\text { [89], } 2007\end{array}$ & 25 & & $\begin{array}{l}\text { PET/CT-based volume } \\
\text { significantly smaller than CT. }\end{array}$ & \\
\hline $\begin{array}{l}\text { Koshy et al. [90], } \\
2005\end{array}$ & 36 & Retrospective & $\begin{array}{l}\text { TNM changed in } 36 \% \text {, RT } \\
\text { volume and dose changed in } 14 \%\end{array}$ & \\
\hline $\begin{array}{l}\text { Heron et al. [91], } \\
2004\end{array}$ & 21 & Prospective & $\begin{array}{l}\text { PET/CT improves delineation of } \\
\text { normal tissues from tumor areas }\end{array}$ & $\begin{array}{l}\mathrm{PET} / \mathrm{CT} \text { improves } \\
\text { staging }\end{array}$ \\
\hline $\begin{array}{l}\text { Ciernik et al. [92], } \\
2003\end{array}$ & $12 \mathrm{HNC}$ of 39 & Retrospective & $\begin{array}{l}\text { PET/CT changed GTV in 50\% } \\
\text { compared to CT }\end{array}$ & \\
\hline $\begin{array}{l}\text { Nishioka et al. } \\
{[93], 2002}\end{array}$ & 21 & & $\begin{array}{l}\text { PET improves GTV, normal } \\
\text { tissue sparing }\end{array}$ & PET alone \\
\hline
\end{tabular}

(IMRT) intensity-modulated radiation therapy, (GTV) gross target volume, (BTV) biological target volume, (LRF) locoregional failure

for PET/CT treatment planning is highly recommended to reduce interobserver variability [96]. Geets et al. compared gradient-based method and threshold-based method in patients with laryngeal cancer. They demonstrated that the gradient-based method is more accurate than the thresholdbased method. The threshold-based method overestimated the true volume by $68 \%(P=.014)$ [97].

Although most authors demonstrated that PET/CT can change the gross tumor volume (GTV) and staging status for radiotherapy planning. Several issues are still to be addressed before the role of PET/CT for IMRT planning and gross tumor volume (GTV) delineation can be clearly defined. Is this change in GTV clinically significant? Can PET/CT provide prognostic information guiding the escalating of the radiation dose to area with higher metabolic activity? Furthermore, is the development of objective and reproducible methods for segmenting PET images achievable? Addressing these issues will help to identify the ultimate impact of this technology in radiation treatment planning which needs subsequent larger experimental studies with clinical outcome and cost-benefit analyses.

\section{Non-FDG PET in Head and Neck Cancer}

PET imaging has become a promising tool for detecting hypoxic subvolumes of tumors. Hypoxia represents a negative prognostic factor for radiation treatment of head and neck cancer where it is associated with a significant resistance to radiochemotherapy [98, 99]. However, mapping hypoxic region of tumor can positively impact on treatment outcome [100]. Several PET tracers have emerged for this purpose like 18F-fluoromisonidazole (18F-FMISO), 18F-labelled fluoroazomycin arabinoside (-[18F]FAZA and 2-(2-nitro-(1)H-imidazol-1-yl)-N-(2,2,3, 3,3-pentafluoropropyl)-acetamide (EF5) [100-102]. Chao et al. demonstrated the feasibility of $\mathrm{Cu}(\mathrm{II})$-diacetyl-bis(N(4)methylthiosemicarbazone) (60Cu-ATSM PET) to create a hypoxia imaging-guided IMRT treatment plan through coregistering hypoxia 60Cu-ATSM PET to the corresponding CT images for radiation therapy of patients with head and neck cancer [103]. At our institution, Souvatzoglou et al. 18F-labelled fluoroazomycin arabinoside (18F-FAZA) as a feasible hypoxic agent in patients with head and neck cancer and demonstrated that FAZA can be potentially used for hypoxia-directed intensity-modulated IMRT dosing patients [104].

While 18-18F-FDG PET is very sensitive head and neck cancers, its specificity is not as high as its sensitivity due to false-positive results in inflammatory or infectious lesions. These lesions are frequent in this area, in particular after treatment by surgery and/or radiotherapy. For this purpose, O-(2-[18F]fluoroethyl)-L-tyrosine (18F-FET) has been introduced and investigated by several groups. Results suggested a possible role for FET in head and neck cancer to differentiate between inflammatory and malignancy in a selective cases. Nevertheless, it should not be used as alternative to FDG due to inferior sensitivity $[105,106]$.

The proliferation marker fluorodeoxythymidine 18F-3deoxy-3-fluorothymidine (18F-FLT) has been investigated by de Langen et al. in 15 patients (including 6 patients with HNC) to evaluate the reproducibility of quantitative $18 \mathrm{~F}$ FLT measurements. The authors showed that quantitative 


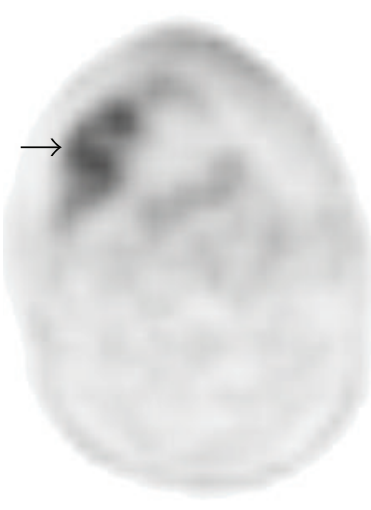

(a)

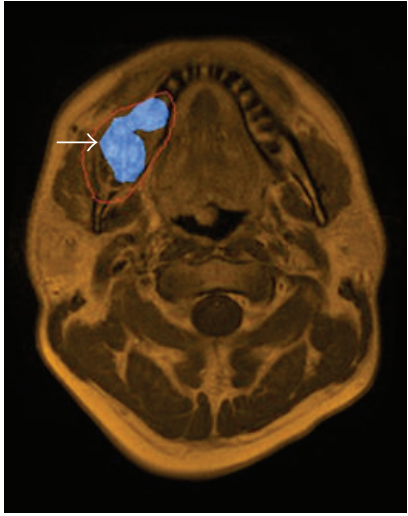

(b)

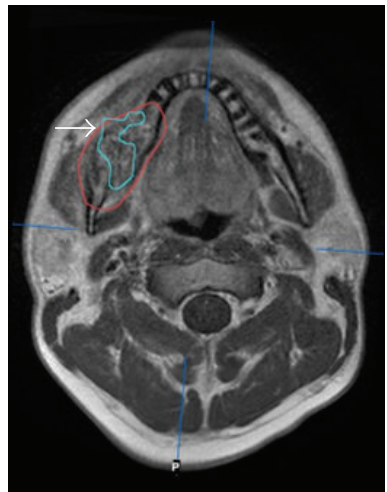

(c)

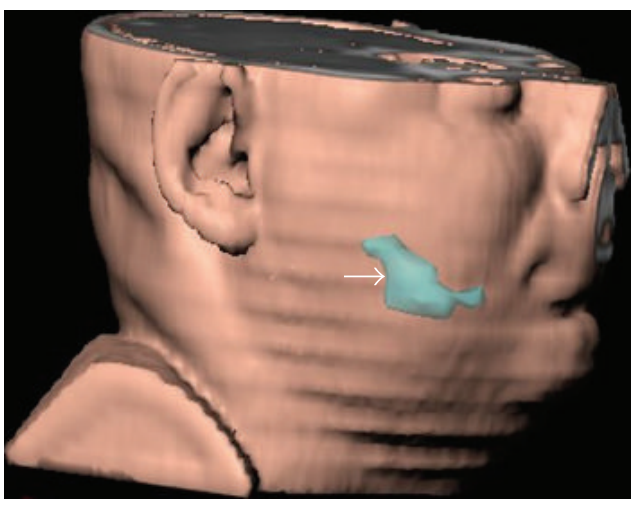

(d)

FIGURE 4: Patient with a squamous cell carcinoma of the right mandible (arrows). (a) The [18F]Galacto-RGD PET shows heterogeneous tracer uptake, which can also be clearly delineated in (b) the image fusion with the corresponding MRI scan. (c) shows the tumour volume in red as defined by MRI. By applying a threshold of SUV 3 and only using pixels with SUVs above this threshold, (d) a subvolume with more intense $\alpha \mathrm{v} ß 3$ expression can be defined which is shown in the 3D reconstruction (blue line in (c), blue area in (d)).

18F-FLT measurements are reproducible for predicting response to therapy in individual patients. However, authors recommended further studies correlating 18F-FLT response with pathological and clinical outcome [107].

Beer et al. investigated the application of [18F] GalactoRGD-PET imaging of $\alpha \mathrm{v} ß 3$ expression, a receptor related to tumor angiogenesis and metastasis, in 11 patients with head and neck squamous cell carcinoma (HNSCC). Their results showed that use of 18F-RGD PET in a multimodalities setting and definition of tumor subvolumes is feasible (Figure 4). The authors suggested that 18F-RGD PET imaging might be used for the assessment of angiogenesis and for planning and response evaluation of $\alpha \mathrm{v} ß 3$ targeted therapies [108].

In the preclinical settings, the role of molecular imaging with PET for monitoring the antiepidermal growth factor receptor (anti-EGFR) inhibitor therapy in solid tumors showing overexpression of EGFR like head and neck squmous cell carcinoma (HNSCC) has been investigated. Several radiopharmaceuticals including the proliferation marker fluorodeoxythymidine (18F-FLT) and the chimeric monoclonal antibody (64CU-DOTA-Cetuximab) have been considered promising for this purpose. However, further clinical and imaging studies are still needed.

\section{Acknowledgments}

The authors would like to thank Dr. Ambros Beer and Dr. Michael Souvatzoglou for their contribution in this article.

\section{References}

[1] A. Jemal, R. Siegel, E. Ward, et al., "Cancer statistics, 2008," CA: Cancer Journal for Clinicians, vol. 58, no. 2, pp. 71-96, 2008.

[2] C.-H. Baek, M. K. Chung, H.-S. Jeong, et al., "The clinical usefulness of 18F-FDG PET/CT for the evaluation of lymph node metastasis in periorbital malignancies," Korean Journal of Radiology, vol. 10, no. 1, pp. 1-7, 2009.

[3] J.-L. Roh, N.-K. Yeo, J. S. Kim, et al., "Utility of 2-[18F] fluoro-2-deoxy-d-glucose positron emission tomography and positron emission tomography/computed tomography imaging in the preoperative staging of head and neck squamous cell carcinoma," Oral Oncology, vol. 43, no. 9, pp. 887-893, 2007.

[4] A. Gordin, A. Golz, M. Daitzchman, et al., "Fluorine-18 fluorodeoxyglucose positron emission tomography/computed tomography imaging in patients with carcinoma of the nasopharynx: diagnostic accuracy and impact on clinical 
management," International Journal of Radiation Oncology Biology Physics, vol. 68, no. 2, pp. 370-376, 2007.

[5] M. R. Kim, J.-L. Roh, J. S. Kim, et al., "Utility of 18Ffluorodeoxyglucose positron emission tomography in the preoperative staging of squamous cell carcinoma of the oropharynx," European Journal of Surgical Oncology, vol. 33, no. 5, pp. 633-638, 2007.

[6] F. Dammann, M. Horger, M. Mueller-Berg, et al., "Rational diagnosis of squamous cell carcinoma of the head and neck region: comparative evaluation of CT, MRI, and 18FDG PET," American Journal of Roentgenology, vol. 184, no. 4, pp. 1326-1331, 2005.

[7] S.-H. Ng, T.-C. Yen, C.-T. Liao, et al., "18F-FDG PET and CT/MRI in oral cavity squamous cell carcinoma: a prospective study of 124 patients with histologic correlation," Journal of Nuclear Medicine, vol. 46, no. 7, pp. 1136-1143, 2005.

[8] P. E. Valk, T. R. Pounds, R. D. Tesar, D. M. Hopkins, and M. K. Haseman, "Cost-effectiveness of PET imaging in clinical oncology," Nuclear Medicine and Biology, vol. 23, no. 6, pp. 737-743, 1996.

[9] C. Scarfone, W. C. Lavely, A. J. Cmelak, et al., "Prospective feasibility trial of radiotherapy target definition for head and neck cancer using 3-dimensional PET and CT imaging," Journal of Nuclear Medicine, vol. 45, no. 4, pp. 543-552, 2004.

[10] P. K. Ha, A. Hdeib, D. Goldenberg, et al., "The role of positron emission tomography and computed tomography fusion in the management of early-stage and advanced-stage primary head and neck squamous cell carcinoma," Archives of Otolaryngology, vol. 132, no. 1, pp. 12-16, 2006.

[11] A. Gordin, M. Daitzchman, I. Doweck, et al., "Fluorodeoxyglucose-positron emission tomography/computed tomography imaging in patients with carcinoma of the larynx: diagnostic accuracy and impact on clinical management," Laryngoscope, vol. 116, no. 2, pp. 273-278, 2006.

[12] G. W. Goerres, D. T. Schmid, K. W. Gratz, G. K. Von Schulthess, and G. K. Eyrich, "Impact of whole body positron emission tomography on initial staging and therapy in patients with squamous cell carcinoma of the oral cavity," Oral Oncology, vol. 39, no. 6, pp. 547-551, 2003.

[13] D. T. Schmid, S. J. Stoeckli, F. Bandhauer, et al., "Impact of positron emission tomography on the initial staging and therapy in locoregional advanced squamous cell carcinoma of the head and neck," Laryngoscope, vol. 113, no. 5, pp. 888891, 2003.

[14] M. P. Stokkel, F.-W. ten Broek, G.-J. Hordijk, R. Koole, and P. P. van Rijk, "Preoperative evaluation of patients with primary head and neck cancer using dual-head 18fluorodeoxyglucose positron emission tomography," Annals of Surgery, vol. 231, no. 2, pp. 229-234, 2000.

[15] B. F. T. Branstetter IV, T. M. Blodgett, L. A. Zimmer, et al., "Head and neck malignancy: is PET/CT more accurate than PET or CT alone?” Radiology, vol. 235, no. 2, pp. 580-586, 2005.

[16] H. Schoder, H. W. Yeung, M. Gonen, D. Kraus, and S. M. Larson, "Head and neck cancer: clinical usefulness and accuracy of PET/CT image fusion," Radiology, vol. 231, no. 1, pp. 65-72, 2004.

[17] R. Syed, J. B. Bomanji, N. Nagabhushan, et al., "Impact of combined 18F-FDG PET/CT in head and neck tumours," British Journal of Cancer, vol. 92, no. 6, pp. 1046-1050, 2005.
[18] A. Hannah, A. M. Scott, H. Tochon-Danguy, et al., "Evaluation of $18 \mathrm{~F}$-fluorodeoxyglucose positron emission tomography and computed tomography with histopathologic correlation in the initial staging of head and neck cancer," Annals of Surgery, vol. 236, no. 2, pp. 208-217, 2002.

[19] S.-H. Ng, T.-C. Yen, J.T. Chang, et al., "Prospective study of [18F]fluorodeoxyglucose positron emission tomography and computed tomography and magnetic resonance imaging in oral cavity squamous cell carcinoma with palpably negative neck," Journal of Clinical Oncology, vol. 24, no. 27, pp. 43714376, 2006.

[20] C.-H. Baek, M. K. Chung, Y.-I. Son, et al., "Tumor volume assessment by 18 F-FDG PET/CT in patients with oral cavity cancer with dental artifacts on CT or MR images," Journal of Nuclear Medicine, vol. 49, no. 9, pp. 1422-1428, 2008.

[21] W. Mendenhall, C. Morris, R. Hinerman, R. S. Malyapa, and R. J. Amdur, "Definitive radiotherapy for nasopharyngeal carcinoma," American Journal of Clinical Oncology, vol. 29, no. 6, pp. 622-627, 2006.

[22] S. Adams, R. P. Baum, T. Stuckensen, K. Bitter, and G. Hör, "Prospective comparison of 18F-FDG PET with conventional imaging modalities (CT, MRI, US) in lymph node staging of head and neck cancer," European Journal of Nuclear Medicine, vol. 25, no. 9, pp. 1255-1260, 1998.

[23] H. Zhuang, R. Kumar, S. Mandel, and A. Alavi, "Investigation of thyroid, head, and neck cancers with PET," Radiologic Clinics of North America, vol. 42, no. 6, pp. 1101-1111, 2004.

[24] A. Quon, N. J. Fischbein, I. R. McDougall, et al., "Clinical role of $18 \mathrm{~F}-\mathrm{FDG}$ PET/CT in the management of squamous cell carcinoma of the head and neck and thyroid carcinoma," Journal of Nuclear Medicine, vol. 48, no. 1, supplement, pp. 58S-67S, 2007.

[25] H. Schöder and H. W. Yeung, "Positron emission imaging of head and neck cancer, including thyroid carcinoma," Seminars in Nuclear Medicine, vol. 34, no. 3, pp. 180-197, 2004.

[26] W. R. Nemzek, S. Hecht, R. Gandour-Edwards, P. Donald, and K. McKennan, "Perineural spread of head and neck tumors: how accurate is MR imaging?” American Journal of Neuroradiology, vol. 19, no. 4, pp. 701-706, 1998.

[27] L. L. Myers, M. K. Wax, H. Nabi, G. T. Simpson, and D. Lamonica, "Positron emission tomography in the evaluation of the N0 neck," Laryngoscope, vol. 108, no. 2, pp. 232-236, 1998.

[28] C. Nahmias, E. R. Carlson, L. D. Duncan, et al., "Positron emission tomography/computerized tomography (PET/CT) scanning for preoperative staging of patients with oral/head and neck cancer," Journal of Oral and Maxillofacial Surgery, vol. 65, no. 12, pp. 2524-2535, 2007.

[29] H. Schoder, D. L. Carlson, D. H. Kraus, et al., "18F-FDG PET/CT for detecting nodal metastases in patients with oral cancer staged N0 by clinical examination and CT/MRI," Journal of Nuclear Medicine, vol. 47, no. 5, pp. 755-762, 2006.

[30] U. Schroeder, M. Dietlein, C. Wittekindt, et al., "Is there a need for positron emission tomography imaging to stage the N0 neck in T1-T2 squamous cell carcinoma of the oral cavity or oropharynx?" Annals of Otology, Rhinology, and Laryngology, vol. 117, no. 11, pp. 854-863, 2008.

[31] A. F. Kovacs, N. Dobert, J. Gaa, C. Menzel, and K. Bitter, "Positron emission tomography in combination with sentinel node biopsy reduces the rate of elective neck dissections in the treatment of oral and oropharyngeal cancer," Journal of Clinical Oncology, vol. 22, no. 19, pp. 3973-3980, 2004. 
[32] B. Rahima, S. Shingaki, M. Nagata, and C. Saito, "Prognostic significance of perineural invasion in oral and oropharyngeal carcinoma," Oral Surgery, Oral Medicine, Oral Pathology, Oral Radiology, and Endodontics, vol. 97, no. 4, pp. 423-431, 2004.

[33] S. Wenzel, C. Sagowski, W. Kehrl, and F. U. Metternich, "The prognostic impact of metastatic pattern of lymph nodes in patients with oral and oropharyngeal squamous cell carcinomas," European Archives of Oto-Rhino-Laryngology, vol. 261, no. 5, pp. 270-275, 2004.

[34] S.-H. Ng, S.-C. Chan, T.-C. Yen, et al., "Staging of untreated nasopharyngeal carcinoma with PET/CT: comparison with conventional imaging work-up," European Journal of Nuclear Medicine and Molecular Imaging, vol. 36, no. 1, pp. 12-22, 2009.

[35] M. L. Chua, S. C. Ong, J. T. Wee, et al., "Comparison of 4 modalities for distant metastasis staging in endemic nasopharyngeal carcinoma," Head and Neck, vol. 31, no. 3, pp. 346-354, 2009.

[36] F.-Y. Liu, C.-Y. Lin, J. T. Chang, et al., "18F-FDG PET can replace conventional work-up in primary $\mathrm{M}$ staging of nonkeratinizing nasopharyngeal carcinoma," Journal of Nuclear Medicine, vol. 48, no. 10, pp. 1614-1619, 2007.

[37] T.-C. Yen, J.T. Chang, S.-H. Ng, et al., "The value of 18FFDG PET in the detection of stage M0 carcinoma of the nasopharynx," Journal of Nuclear Medicine, vol. 46, no. 3, pp. 405-410, 2005.

[38] M. B. Sigg, H. Steinert, K. Gratz, P. Hugenin, S. Stoeckli, and G. K. Eyrich, "Staging of head and neck tumors: [18F]fluorodeoxyglucose positron emission tomography compared ith physical examination and conventional imaging modalities," Journal of Nuclear Medicine, vol. 61, pp. 1022-1029, 2003.

[39] D. L. Schwartz, J. Rajendran, B. Yueh, et al., "Staging of head and neck squamous cell cancer with extended-field FDGPET," Archives of Otolaryngology, vol. 129, no. 11, pp. 11731178, 2003.

[40] C. Grau, L. V. Johansen, J. Jakobsen, P. Geertsen, E. Andersen, and B. B. Jensen, "Cervical lymph node metastases from unknown primary tumours: results from a national survey by the Danish Society for Head and Neck Oncology," Radiotherapy and Oncology, vol. 55, no. 2, pp. 121-129, 2000.

[41] D. Beldì, B. A. Jereczek-Fossa, A. D’Onofrio, et al., "Role of radiotherapy in the treatment of cervical lymph node metastases from an unknown primary site: retrospective analysis of 113 patients," International Journal of Radiation Oncology Biology Physics, vol. 69, no. 4, pp. 1051-1058, 2007.

[42] L. Zimmer, B. Branstetter, J. Nayak, and J. T. Johnson, "Current use of 18F-fluorodeoxyglucose positron emission tomography and combined positron emission tomography and computed tomography in squamous cell carcinoma of the head and neck," Laryngoscope, vol. 115, no. 11, pp. 20292034, 2005.

[43] W. M. Mendenhall, A. A. Mancuso, R. J. Amdur, S. P. Stringer, D. B. Villaret, and N. J. Cassisi, "Squamous cell carcinoma metastatic to the neck from an unknown head and neck primary site," American Journal of Otolaryngology, vol. 22, no. 4, pp. 261-267, 2001.

[44] C. Schmalbach and F. Miller, "Occult primary head and neck carcinoma," Current Oncology Reports, vol. 9, no. 2, pp. 139$146,2007$.

[45] K. E. Rusthoven, M. Koshy, and A. C. Paulino, "The role of fluorodeoxyglucose positron emission tomography in cervical lymph node metastases from an unknown primary tumor," Cancer, vol. 101, no. 11, pp. 2641-2649, 2004.
[46] D. Padovani, C. Aimoni, P. Zucchetta, A. Paluzzi, and A. Pastore, "18-FDG PET in the diagnosis of laterocervical metastases from occult carcinoma," European Archives of OtoRhino-Laryngology, vol. 266, no. 2, pp. 267-271, 2009.

[47] P. Silva, P. Hulse, A. J. Sykes, et al., "Should FDG-PET scanning be routinely used for patients with an unknown head and neck squamous primary?" Journal of Laryngology and Otology, vol. 121, no. 2, pp. 149-153, 2007.

[48] N. Fakhry, T. Jacob, J. Paris, et al., "Contribution of 18-FFDG PET for detection of head and neck carcinomas with an unknown primary tumor," Ann Otolaryngol Chir Cervicofac, vol. 123, no. 1, pp. 17-25, 2006.

[49] W. L. Wong and M. Saunders, "The impact of FDG PET on the management of occult primary head and neck tumours," Clinical Oncology, vol. 15, no. 8, pp. 461-466, 2003.

[50] G. B. Fogarty, L. J. Peters, J. Stewart, C. Scott, D. Rischin, and R. J. Hicks, "The usefulness of fluorine 18-labelled deoxyglucose positron emission tomography in the investigation of patients with cervical lymphadenopathy from an unknown primary tumor," Head and Neck, vol. 25, no. 2, pp. 138-145, 2003.

[51] J. Johansen, A. Eigtved, C. Buchwald, S. A. Theilgaard, and H. S. Hansen, "Implication of 18F-fluoro-2-deoxy-Dglucose positron emission tomography on management of carcinoma of unknown primary in the head and neck: a Danish cohort study," Laryngoscope, vol. 112, no. 11, pp. 2009-2014, 2002.

[52] E. Kresnik, P. Mikosch, H. J. Gallowitsch, et al., "Evaluation of head and neck cancer with 18 F-FDG pet: a comparison with conventional methods," European Journal of Nuclear Medicine, vol. 28, no. 7, pp. 816-821, 2001.

[53] M. Jungehulsing, K. Scheidhauer, M. Damm, et al., "2[F]fluoro-2-deoxy-D-glucose positron emission tomography is a sensitive tool for the detection of occult primary cancer (carcinoma of unknown primary syndrome) with head and neck lymph node manifestation," Otolaryngology, vol. 123, no. 3, pp. 294-301, 2000.

[54] J. Johansen, S. Buus, A. Loft, et al., "Prospective study of 18FDG-PET in the detection and management of patients with lymph node metastases to the neck from an unknown primary tumor: results from the Dahanca-13 study," Head and Neck, vol. 30, no. 4, pp. 471-478, 2008.

[55] J.-L. Roh, J. S. Kim, J. H. Lee, et al., "Utility of combined 18F-fluorodeoxyglucose-positron emission tomography and computed tomography in patients with cervical metastases from unknown primary tumors," Oral Oncology, vol. 45, no. 3, pp. 218-224, 2009.

[56] D. J. Adelstein, Y. Li, G. L. Adams, et al., "An intergroup phase III comparison of standard radiation therapy and two schedules of concurrent chemoradiotherapy in patients with unresectable squamous cell head and neck cancer," Journal of Clinical Oncology, vol. 21, no. 1, pp. 92-98, 2003.

[57] R. C. Martin, M. Fulham, K. F. Shannon, et al., "Accuracy of positron emission tomography in the evaluation of patients treated with chemoradiotherapy for mucosal head and neck cancer," Head and Neck, vol. 31, no. 2, pp. 244-250, 2009.

[58] R. A. Velazquez, H. S. McGuff, D. Sycamore, and F. R. Miller, "The role of computed tomographic scans in the management of the n-positive neck in head and neck squamous cell carcinoma after chemoradiotherapy," Archives of Otolaryngology, vol. 130, no. 1, pp. 74-77, 2004. 
[59] A. D. Bronstein, D. A. Nyberg, A. N. Schwartz, W. P. Shuman, and B. R. Griffin, "Soft-tissue changes after head and neck radiation: CT findings," American Journal of Neuroradiology, vol. 10, no. 1, pp. 171-175, 1989.

[60] C. H. Terhaard, V. Bongers, P. P. van Rijk, and G.-J. Hordijk, "F-18-fluoro-deoxy-glucose positron-emission tomography scanning in detection of local recurrence after radiotherapy for laryngeal/pharyngeal cancer," Head and Neck, vol. 23, no. 11, pp. 933-941, 2001.

[61] K. M. Greven, D. W. Williams III, W. F. McGuirt Sr., et al., "Serial positron emission tomography scans following radiation therapy of patients with head and neck cancer," Head and Neck, vol. 23, no. 11, pp. 942-946, 2001.

[62] K. M. Greven, D. W. Williams, J. W. Keyes Jr., et al., "Positron emission tomography of patients with head and neck carcinoma before and after high dose irradiation," Cancer, vol. 74, no. 4, pp. 1355-1359, 1994.

[63] A. Gordin, A. Golz, Z. Keidar, M. Daitzchman, R. BarShalom, and O. Israel, "The role of FDG-PET/CT imaging in head and neck malignant conditions: impact on diagnostic accuracy and patient care," Otolaryngology, vol. 137, no. 1, pp. 130-137, 2007.

[64] C. Conessa, S. Hervé, H. Foehrenbach, and J.-L. Poncet, "FDG-PET scan in local follow-up of irradiated head and neck squamous cell carcinomas," Annals of Otology, Rhinology, and Laryngology, vol. 113, no. 8, pp. 628-635, 2004.

[65] Y. Kitagawa, S. Nishizawa, and K. Sano, "Prospective comparison of ${ }^{18} \mathrm{~F}$-FDG PET with conventional imaging modalities (MRI, CT, and ${ }^{67} \mathrm{Ga}$ scintigraphy) in assessment of combined intraarterial chemotherapy and radiotherapy for head and neck carcinoma," Journal of Nuclear Medicine, vol. 44, no. 2, pp. 198-206, 2003.

[66] M. Yao, R. B. Smith, M. M. Graham, et al., "The role of FDG PET in management of neck metastasis from head-and-neck cancer after definitive radiation treatment," International Journal of Radiation Oncology Biology Physics, vol. 63, no. 4, pp. 991-999, 2005.

[67] M. Stokkel, C. Terhaard, I Mertens, I.-J. Hordijk, and P. P. van Rijk, "Fluorine-18-FDG detection of laryngeal cancer postradiotherapy using dual-head coincidence imaging," Journal of Nuclear Medicine, vol. 39, no. 8, pp. 1385-1387, 1998.

[68] S. Y. Kim, S.-W. Lee, S. W. Nam, et al., "The feasibility of 18F-FDG PET scans 1 month after completing radiotherapy of squamous cell carcinoma of the head and neck," Journal of Nuclear Medicine, vol. 48, no. 3, pp. 373-378, 2007.

[69] D. Delbeke and W. H. Martin, "Positron emission tomography imaging in oncology," Radiologic Clinics of North America, vol. 39, no. 5, pp. 883-917, 2001.

[70] L. Kostakoglu and S. J. Goldsmith, "PET in the assessment of therapy response in patients with carcinoma of the head and neck and of the esophagus," Journal of Nuclear Medicine, vol. 45 , no. 1, pp. 56-68, 2004.

[71] J. W. Rogers, K. M. Greven, W. F. McGuirt, et al., "Can post-rt neck dissection be omitted for patients with head-and-neck cancer who have a negative pet scan after definitive radiation therapy?" International Journal of Radiation Oncology Biology Physics, vol. 58, no. 3, pp. 694-697, 2004.

[72] S. C. Ong, H. Schöder, N. Y. Lee, et al., "Clinical utility of 18F-FDG PET/CT in assessing the neck after concurrent chemoradiotherapy for locoregional advanced head and neck cancer," Journal of Nuclear Medicine, vol. 49, no. 4, pp. 532540, 2008.
[73] M. Yao, R. B. Smith, H. T. Hoffman, et al., "Clinical significance of postradiotherapy [18F]-fluorodeoxyglucose positron emission tomography imaging in management of head-and-neck cancer-a long-term outcome report," International Journal of Radiation Oncology Biology Physics, vol. 74, no. 1, pp. 9-14, 2009.

[74] A. Tan, D. Adelstein, L. Rybicki, et al., "Ability of positron emission tomography to detect residual neck node disease in patients with head and neck squamous cell carcinoma after definitive chemoradiotherapy," Archives of Otolaryngology, vol. 133, no. 5, pp. 435-440, 2007.

[75] B. M. Klabbers, A. A. Lammertsma, and B. J. Slotman, "The value of positron emission tomography for monitoring response to radiotherapy in head and neck cancer," Molecular Imaging and Biology, vol. 5, no. 4, pp. 257-270, 2003.

[76] W. R. Ryan, W. E. Fee Jr., Q.-T. Le, and H. A. Pinto, "Positronemission tomography for surveillance of head and neck cancer," Laryngoscope, vol. 115, no. 4, pp. 645-650, 2005.

[77] R. Abgral, S. Querellou, G. Potard, et al., "Does ${ }^{18}$ F-FDG PET/CT improve the detection of posttreatment recurrence of head and neck squamous cell carcinoma in patients negative for disease on clinical follow-up?" Journal of Nuclear Medicine, vol. 50, no. 1, pp. 24-29, 2009.

[78] Y.-F. Wang, R.-S. Liu, P.-Y. Chu, et al., "Positron emission tomography in surveillance of head and neck squamous cell carcinoma after definitive chemoradiotherapy," Head and Neck, vol. 31, no. 4, pp. 442-451, 2009.

[79] T. F. Cermik, A. Mavi, G. Acikgoz, M. Houseni, S. Dadparvar, and A. Alavi, "FDG PET in detecting primary and recurrent malignant salivary gland tumors," Clinical Nuclear Medicine, vol. 32, no. 4, pp. 286-291, 2007.

[80] R. M. Álvarez Pérez, I. Borrego Dorado, J.V. Ruiz FrancoBaux, and R. J. Vázquez Albertino, "Evaluation of efficacy and clinical impact of positron emission tomography with $18 \mathrm{~F}$ fluoro-deoxyglucose in patients with suspicion of recurrent head and neck cancer or distant metastases," Revista Espanola de Medicina Nuclear, vol. 26, no. 1, pp. 30-39, 2007.

[81] P. Y. Salaun, R. Abgral, S. Querellou, et al., "Does 18fluorofluorodeoxyglucose positron emission tomography improve recurrence detection in patients treated for head and neck squamous cell carcinoma with negative clinical follow-up?" Head and Neck, vol. 29, no. 12, pp. 1115-1120, 2007.

[82] G. W. Goerres, D. T. Schmid, F. Bandhauer, et al., "Positron emission tomography in the early follow-up of advanced head and neck cancer," Archives of Otolaryngology, vol. 130, no. 1, pp. 105-109, 2004.

[83] K. Kubota, J. Yokoyama, K. Yamaguchi, et al., "FDGPET delayed imaging for the detection of head and neck cancer recurrence after radio-chemotherapy: comparison with MRI/CT," European Journal of Nuclear Medicine and Molecular Imaging, vol. 31, no. 4, pp. 590-595, 2004.

[84] R. J. Wong, "Current status of FDG-PET for head and neck cancer," Journal of Surgical Oncology, vol. 97, no. 8, pp. 649652, 2008.

[85] D. E. Soto, M. L. Kessler, M. Piert, and A. Eisbruch, "Correlation between pretreatment FDG-PET biological target volume and anatomical location of failure after radiation therapy for head and neck cancers," Radiotherapy and Oncology, vol. 89, no. 1, pp. 13-18, 2008.

[86] S. Rothschild, G. Studer, B. Seifert, et al., "PET/CT staging followed by intensity-modulated radiotherapy (IMRT) improves treatment outcome of locally advanced pharyngeal carcinoma: a matched-pair comparison," Radiation Oncology, vol. 2, no. 1, 2007. 
[87] D. Wang, C. J. Schultz, P. A. Jursinic, et al., "Initial experience of FDG-PET/CT guided IMRT of head-andneck carcinoma," International Journal of Radiation Oncology Biology Physics, vol. 65, no. 1, pp. 143-151, 2006.

[88] S. L. Breen, J. Publicover, S. De Silva, et al., "Intraobserver and interobserver variability in GTV delineation on FDGPET-CT images of head and neck cancers," International Journal of Radiation Oncology Biology Physics, vol. 68, no. 3, pp. 763-770, 2007.

[89] M. El-Bassiouni, I. F. Ciernik, J. B. Davis, et al., "[18FDG] PET-CT-based intensity-modulated radiotherapy treatment planning of head and neck cancer," International Journal of Radiation Oncology Biology Physics, vol. 69, no. 1, pp. 286293, 2007.

[90] M. Koshy, A. C. Paulino, R. Howell, D. Schuster, R. Halkar, and L. W. Davis, "F-18 FDG PET-CT fusion in radiotherapy treatment planning for head and neck cancer," Head and Neck, vol. 27, no. 6, pp. 494-502, 2005.

[91] D. E. Heron, R. S. Andrade, J. Flickinger, et al., "Hybrid PETCT simulation for radiation treatment planning in head-andneck cancers: a brief technical report," International Journal of Radiation Oncology Biology Physics, vol. 60, no. 5, pp. 14191424, 2004.

[92] I. F. Ciernik, E. Dizendorf, B. G. Baumert, et al., "Radiation treatment planning with an integrated positron emission and computer tomography (PET/CT): a feasibility study," International Journal of Radiation Oncology Biology Physics, vol. 57, no. 3, pp. 853-863, 2003.

[93] T. Nishioka, T. Shiga, H. Shirato, et al., "Image fusion between 18FDG-PET and MRI/CT for radiotherapy planning of oropharyngeal and nasopharyngeal carcinomas," International Journal of Radiation Oncology Biology Physics, vol. 53, no. 4, pp. 1051-1057, 2002.

[94] P. H. Ahn and M. K. Garg, "Positron emission tomography/computed tomography for target delineation in head and neck cancers," Seminars in Nuclear Medicine, vol. 38, no. 2, pp. 141-148, 2008.

[95] A. C. Paulino and P. A. Johnstone, "18F-FDG PET in radiotherapy treatment planning: Pandora's box?” International Journal of Radiation Oncology Biology Physics, vol. 59, no. 2, pp. 4-5, 2004.

[96] A. M. Berson, N. F. Stein, A. C. Riegel, et al., "Variability of gross tumor volume delineation in head-and-neck cancer using PET/CT fusion, part II: the impact of a contouring protocol," Medical Dosimetry, vol. 34, no. 1, pp. 30-35, 2009.

[97] X. Geets, J. A. Lee, A. Bol, M. Lonneux, and V. Grégoire, "A gradient-based method for segmenting FDG-PET images: methodology and validation," European Journal of Nuclear Medicine and Molecular Imaging, vol. 34, no. 9, pp. 14271438, 2007.

[98] M. Nordsmark, S. M. Bentzen, V. Rudat, et al., "Prognostic value of tumor oxygenation in 397 head and neck tumors after primary radiation therapy: an international multicenter study," Radiotherapy and Oncology, vol. 77, no. 1, pp. 18-24, 2005.

[99] B. J. Krause, R. Beck, M. Souvatzoglou, and M. Piert, "PET and PET/CT studies of tumor tissue oxygenation," Quarterly Journal of Nuclear Medicine and Molecular Imaging, vol. 50, no. 1, pp. 28-43, 2006.

[100] J. Dunst, P. Stadler, A. Becker, et al., "Tumor volume and tumor hypoxia in head and neck cancers: the amount of the hypoxic volume is important," Strahlentherapie und Onkologie, vol. 179, no. 8, pp. 521-526, 2003.
[101] S. T. Lee and A. M. Scott, "Hypoxia positron emission tomography imaging with $18 \mathrm{~F}$-fluoromisonidazole," Seminars in Nuclear Medicine, vol. 37, no. 6, pp. 451-461, 2007.

[102] G. Komar, M. Seppänen, O. Eskola, et al., "18F-EF5: a new PET tracer for imaging hypoxia in head and neck cancer," Journal of Nuclear Medicine, vol. 49, no. 12, pp. 1944-1951, 2008.

[103] K. S. Chao, W. R. Bosch, S. Mutic, et al., "A novel approach to overcome hypoxic tumor resistance: Cu-ATSM-guided intensity-modulated radiation therapy," International Journal of Radiation Oncology Biology Physics, vol. 49, no. 4, pp. 1171-1182, 2001.

[104] M. Souvatzoglou, A. L. Grosu, B. Röper, et al., "Tumour hypoxia imaging with [18F]FAZA PET in head and neck cancer patients: a pilot study," European Journal of Nuclear Medicine and Molecular Imaging, vol. 34, no. 10, pp. 15661575, 2007.

[105] S. Balogova, S. Périé, K. Kerrou, et al., "Prospective comparison of FDG and FET PET/CT in patients with head and neck squamous cell carcinoma," Molecular Imaging and Biology, vol. 10, no. 6, pp. 364-373, 2008.

[106] D. Pauleit, A. Zimmermann, G. Stoffels, et al., "18F-FET PET compared with18F-FDG PET and CT in patients with head and neck cancer," Journal of Nuclear Medicine, vol. 47, no. 2, pp. 256-261, 2006.

[107] A. J. de Langen, B. Klabbers, M. Lubberink, et al., "Reproducibility of quantitative $18 \mathrm{~F}-3^{\prime}$-deoxy- $3^{\prime}$ - fluorothymidine measurements using positron emission tomography," European Journal of Nuclear Medicine and Molecular Imaging, vol. 36, no. 3, pp. 389-395, 2009.

[108] A. J. Beer, A.-L. Grosu, J. Carlsen, et al., “[18F]GalactoRGD positron emission tomography for imaging of $\alpha \mathrm{v} \beta 3$ expression on the neovasculature in patients with squamous cell carcinoma of the head and neck," Clinical Cancer Research, vol. 13, no. 22, pp. 6610-6616, 2007. 


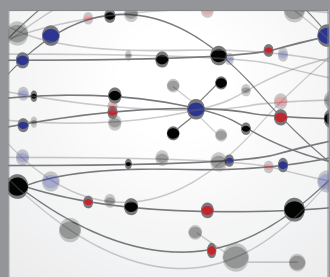

The Scientific World Journal
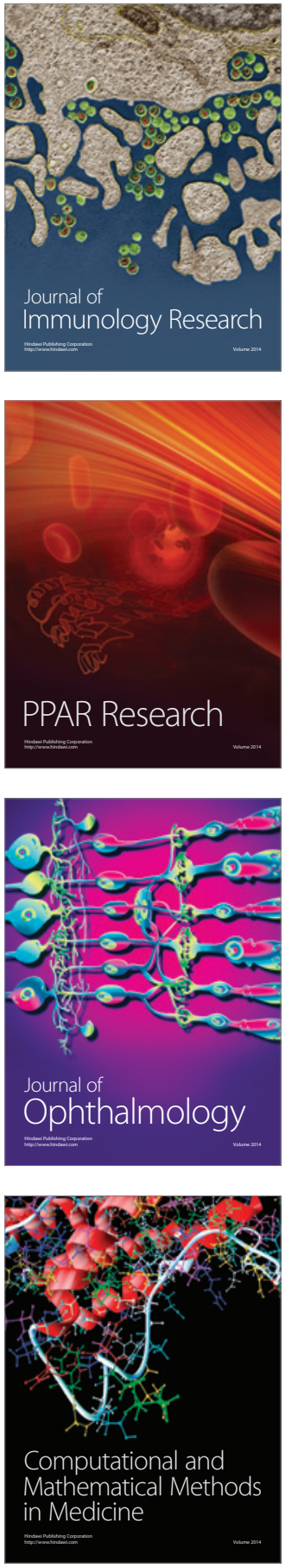

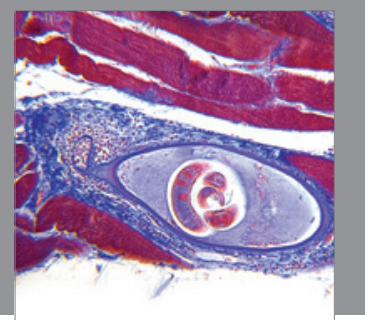

Gastroenterology

Research and Practice
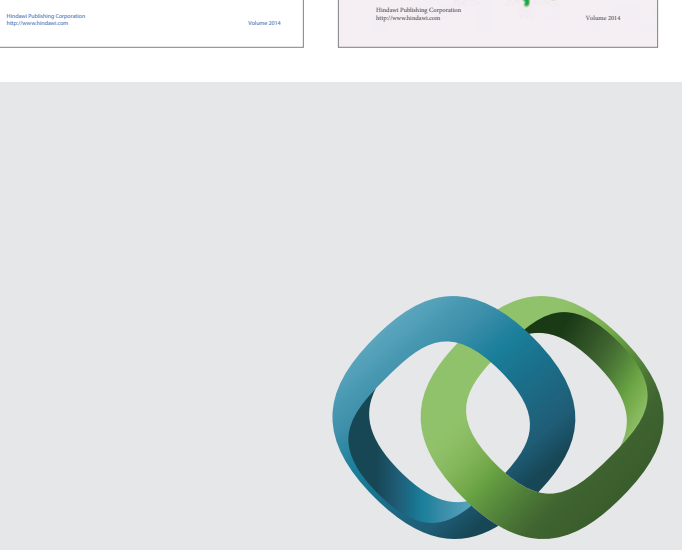

\section{Hindawi}

Submit your manuscripts at

http://www.hindawi.com
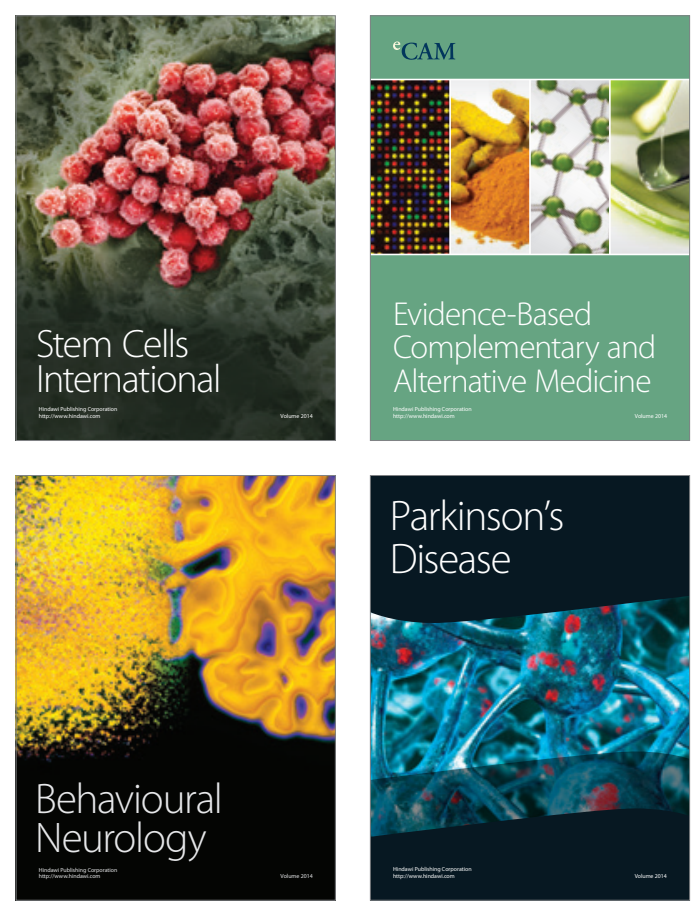

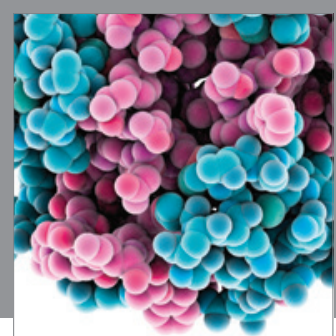

Journal of
Diabetes Research

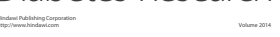

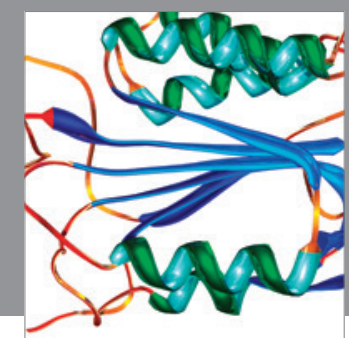

Disease Markers
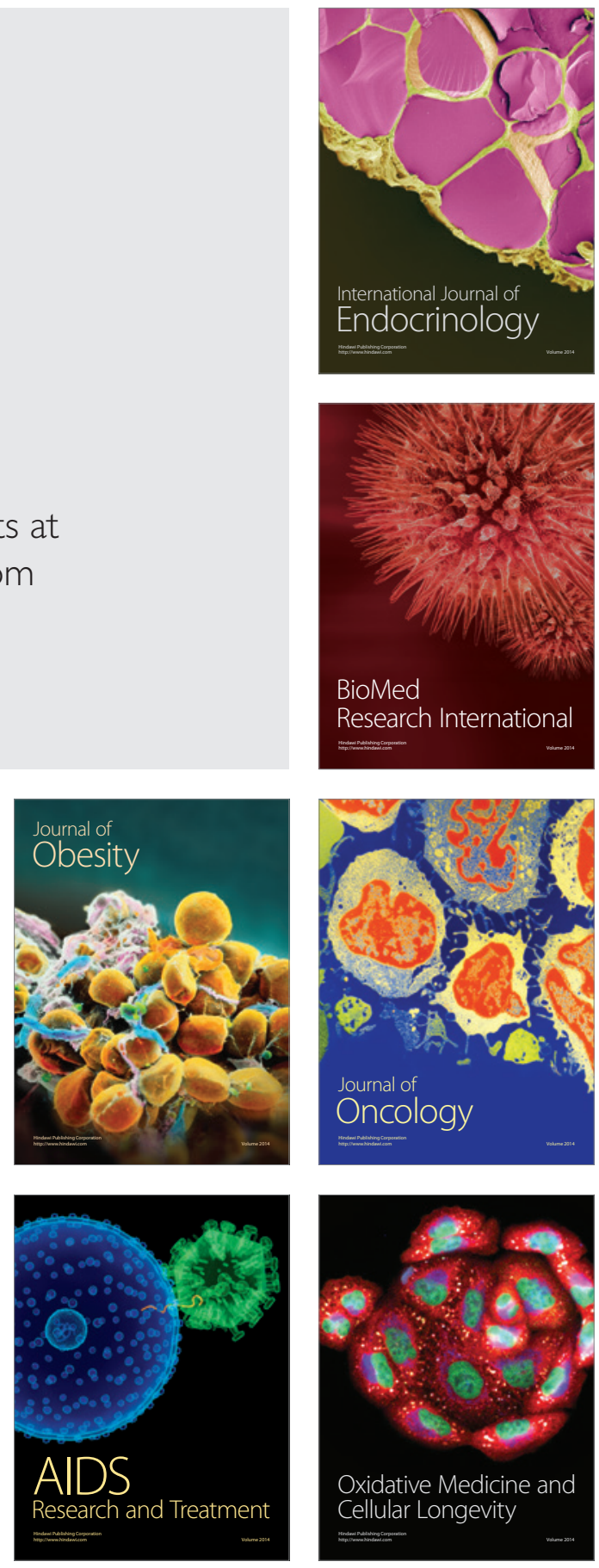